ournal of

\title{
Brain MRI Features in Horizontal Gaze Palsy with Progressive Scoliosis
}

\author{
Mostafa Almasi ${ }^{1}$, Mohammad Rohani ${ }^{1}$, Mostafa Soltan Sanjari ${ }^{2}$ and Atefeh Imani ${ }^{3^{*}}$ \\ ${ }^{1}$ Department of Neurology, Faculty of Medicine, Iran University of Medical Sciences, Iran \\ ${ }^{2}$ Department of Ophthalmology, Faculty of Medicine, Iran University of Medical Sciences, Iran \\ ${ }^{3}$ Faculty of Medicine, Islamic Azad University, Mashbad Branch, Iran
}

\section{Correspondence to:}

Atefeh Imani

Neurology ward, Rasool-Akram Hospital

Niayesh St, Sattar-khan St, Tehran, Iran

Tel: +98-2164352496

E-mail: Atefeh.imani2017@gmail.com

Received: February 04, 2017

Accepted: April 27, 2017

Published: April 28, 2017

Citation: Almasi M, Rohani M, Soltan Sanjari M, Imani A. 2017. Brain MRI Features in Horizontal Gaze Palsy with Progressive Scoliosis. J Neuroimaging Psychiatry Neurol 2(1): 1-2.

Copyright: () 2017 Almasi et al. This is an Open Access article distributed under the terms of the Creative Commons Attribution 4.0 International License (CC-BY) (http://creativecommons. org/licenses/by/4.0/) which permits commercial use, including reproduction, adaptation, and distribution of the article provided the original author and source are credited.

Published by United Scientific Group

\begin{abstract}
Horizontal gaze palsy with progressive scoliosis (HGPPS) is a rare disease with characteristic imaging features. We report a teenager girl with severe kyphoscoliosis and bilateral horizontal gaze palsy with normal other neurologic examination. The brain MRI revealed "tented" pons and "butterfly-shape" medulla. These changes are due to agenesis of deep structures of brainstem which play important roles in horizontal gaze and proprioception.
\end{abstract}

\section{Keywords}

Horizontal gaze palsy, Progressive scoliosis, MRI features

\section{Case Report}

A 17-years old girl referred to our hospital for repair of scoliosis. The scoliosis began since 2 years ago with a progressive course and created much disability in patient's daily life. Beside severe kyphoscoliosis (Figure 1), she had bilateral horizontal gaze palsy, but the other neurologic examinations including facial expression, pupil size and reaction, convergence, vertical gaze and other eye movements were normal (Figure 2). It was not possible to overcome to limitation of horizontal gaze with vestibuloocular maneuver. She had no birth difficulty or developmental delay and her intelligence and school performance were intact. Her sister had also scoliosis in her teens but the family denied any other neurologic problem.

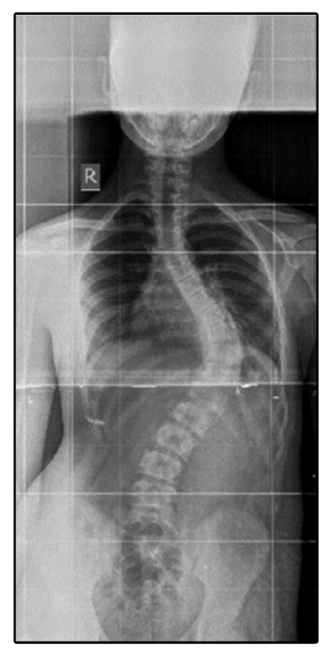

Figure 1: Antero posterior view of X-ray shows severe scoliosis. 

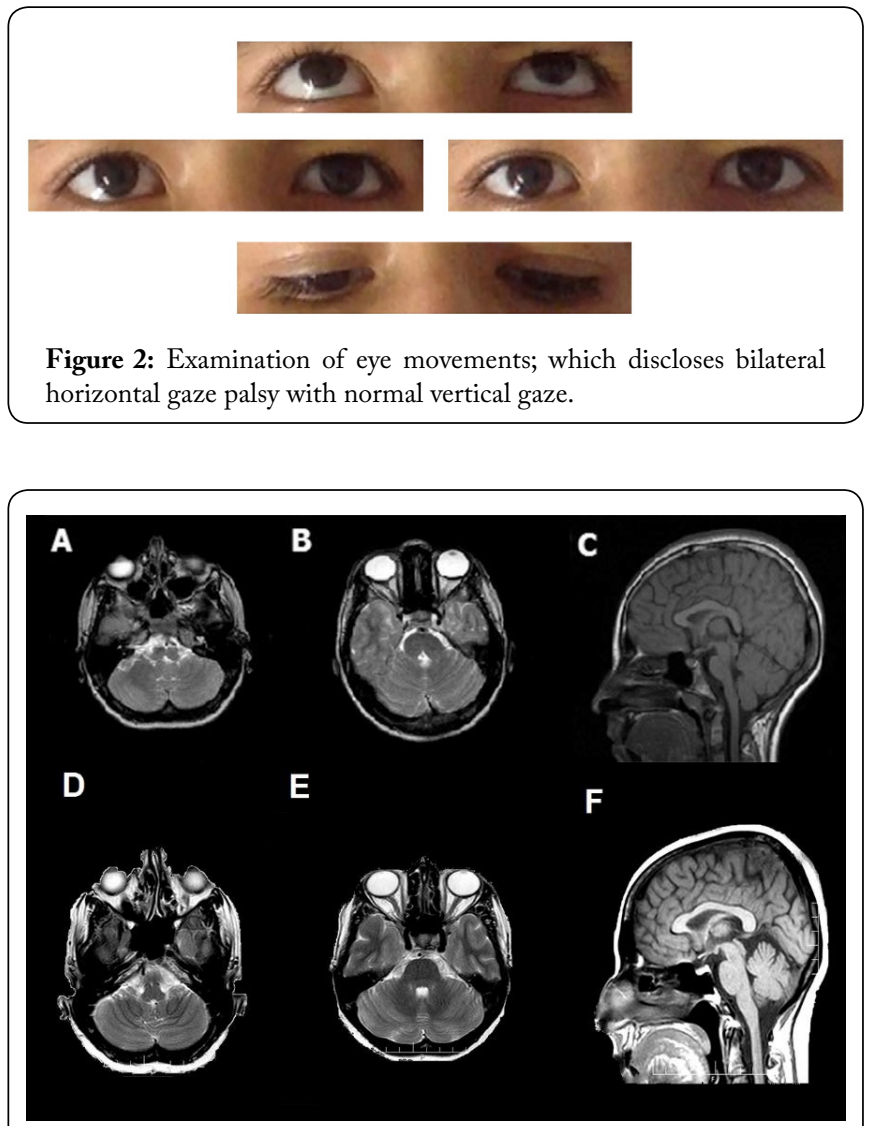

Figure 3: Axial T2 and Sagittal T1-weighted MRI of the patient, atrophy of medulla with a butterfly-shape (A); dorsal midline cleft and tented pons (B); and absence of facial colliculi (C). Axial T2 and Sagittal T1-weighted MRI of a normal subject at the similar anatomic levels, including the medulla (D), the pons (E) and the sagittal midline of brainstem $(\mathbf{F})$.

The brain MRI showed significant pontine and medullary atrophy with "tented" pons and "butterfly-shape" medulla appearances (Figure 3A and 3B). Absence of facial colliculi in the floor of forth ventricle are prominent at the sagittal plan of brain stem (Figure 3C). Based on clinical features and typical brain imaging features, the diagnosis of "Horizontal gaze palsy with progressive scoliosis" (HGPPS) was made; although unfortunately the patient lost the follow-up without any future investigations, including genetic study.

Horizontal gaze palsy with progressive scoliosis (HGPPS) is a rare disease with bilateral horizontal gaze palsy and severe scoliosis and characteristic imaging features [1]. The absence of facial colliculi which is an anatomic structure at the floor of forth ventricle is due to selective agenesis of abducens nuclei [2] and gives rise to the picture of "a tent" to pons. In addition to abducens nuclei, maldevelopment of medial longitudinal fasciculus may lead to a dorsal midline cleft along the pons $[2,3]$. Also there is a ventral midline medullary cleft which is thought to be as the result of uncrossed corticospinal fibers [4]. The gracilis and cuneatus nuclei and medial lemniscus are absent in HGPPS and lead to a prominent decrease in the size of medulla oblongata [3]. All of these structures are a part of proprioceptive systems that can explain the scoliosis.

\section{References}

1. Rohani M, Almasi M, Soltan Sanjari M. 2016. Familial horizontal gaze palsy with progressive scoliosis. Pediatric Neurology 64: 103-104. https://doi.org/10.1016/j.pediatrneurol.2016.08.021

2. dos Santos A, Matias S, Saraiva P, Goulão A. 2006. MR imaging features of brain stem hypoplasia in familial horizontal gaze palsy and scoliosis. AJNR Am J Neuroradiol 27(6): 1382-1383.

3. Bomfim RC, Távora DG, Nakayama M, Gama RL. 2009. Horizontal gaze palsy with progressive scoliosis: CT and MR findings. Pediatr Radiol 39(2): 184-187. https://doi.org/10.1007/s00247-008-1058-8

4. Jen JC, Chan W-M, Bosley TM, Wan J, Carr JR, et al. 2004. Mutations in a human ROBO gene disrupt hindbrain axon pathway crossing and morphogenesis. Science 304(5676): 1509-1513.https://doi.org/10.1126/ science. 1096437 